\title{
Synthesis of Spiro[4.4]Nonane-1,6-Diols via the Hydrogenation of Spiro[4.4]Nonane-1,6-Dione: the Profound Effect of Hydrogenating Agents
}

\author{
Albert S. C. Chan*, Chi-Ching Lin \\ apepartment of Applied Biology and Chemical Technology, the Hong Kong Polytechnic University, Hong Kong; \\ Jian Sun, Wenhao Hu, Zhi Li, Weidong Pan, Alqiao Mi, Yaozhong Jiang* \\ ${ }^{b}$ Chengdu Institute of Organic Chemistry, Chinese Academy of Sciences, Chengdu, China; \\ Tsang-Miao Huang, Teng-Kuei Yang*, Jyh-Horung Chen* \\ CDepartment of Chemistry, National Chung Hsing University, Taichung; \\ Yu Wang, Gene-Hsiang Lee \\ Department of Chemistry, National Taiwan University, Taipei, Taiwan. \\ a,b,c Union Laboratory of Asymmetric Synthesis.
}

\begin{abstract}
The synthesis of spiro[4.4]nonane-1,6-diols via the catalytic as well as stoichiometric hydrogenation of spiro[4.4]nonane-1,6-dione was studied. Profound effects of the hydrogenation catalysts and reagents on the stereoselectivity of the products were observed. The choice of solvent also was found to have a significant influence on the product selectivity. The opening of a spiro-ring in the starting material was identified as a major side reaction in alcohol solvents. The absolute configuration of the trans,trans-diol was unambiguously determined by $\mathrm{X}$ ray crystallography.
\end{abstract}

\section{Introduction}

The use of chiral auxiliaries in metal-mediated asymmetric synthesis (including asymmetric catalysis) has been an area of active research in the past two decades. ${ }^{1}$ Recently there has been increased interest in the synthesis of spirocyclic diols with C2 symmetry. ${ }^{2}$ The use of (+)-1R, 5S, 6R-and (-)-1S, 5R, 6Sspiro[4.4]nonane-1,6-diols ${ }^{3}$ as chiral ligands in the preparation of modified aluminum hydrides gave highly enantioselective reagents for the asymmetric reduction of aromatic ketones. ${ }^{4}$ Because of the intrinsically skewed position of the bicyclic rings in the spirocyclic diols, these compounds may also be excellent precursors for other interesting chiral ligands such as organophosphines and amines. Previously, chiral phosphine ligands containing skewed backbones such as 2,2'-bis(diphenylphosphino)-1,1'-binaphthyl (BINAP), 2,2'bis(dicyclohexylphosphino)-6,6'-dimethyl-1,1'-biphenyl (BICEP), etc., have been found to be highly effective and versatile in inducing the transition-metal catalyzed asymmetric transformations. ${ }^{5}$ Because of the potential of the use of spiro[4.4]nonane-1,6-diols, either as chiral ligands themselves or as precursors to other useful chiral ligands, there is a great incentive in a detailed study of the synthesis of these diols. All three isomers (cis, cis-; cis, trans-; and trans, trans-) are of interest for different purposes. The cis, cis-isomer is most useful as a chelating ligand. When it is used as an intermediate for the preparation of other ligands such as organophosphines or amines, it is usually converted to the trans,trans-isomer through the inversion of the stereogenic centers. The trans, trans-isomer may be a good intermediate for the preparation of cis,cis-bidentate chelating chiral phosphines or amines through $\mathrm{S}_{\mathrm{N}} 2$ displacement of the corresponding mesylate. The cis,transisomers fall in-between and may also be used as chelating ligands. 
In this paper we report the profound effects of reagents and reaction conditions on the product selectivity in the hydrogenation of spiro[4.4]nonane-1,6-dione for the synthesis of spiro[4.4]nonane-1,6-diols. The resolution and unambiguous characterization of the trans,trans-spiro[4.4]nonane-1,6-diol by single crystal Xray diffraction is also discussed.

\section{Results and discussion}

For a broad comparison of synthetic methods, both catalytic and stoichiometric hydrogenations of spiro[4.4]nonane-1,6-dione have been carried out. Interestingly, both the reagents and the solvents have been found to have significant effects on the rate and selectivity of the hydrogenation. On the other hand, the effect of reaction temperature was less profound.

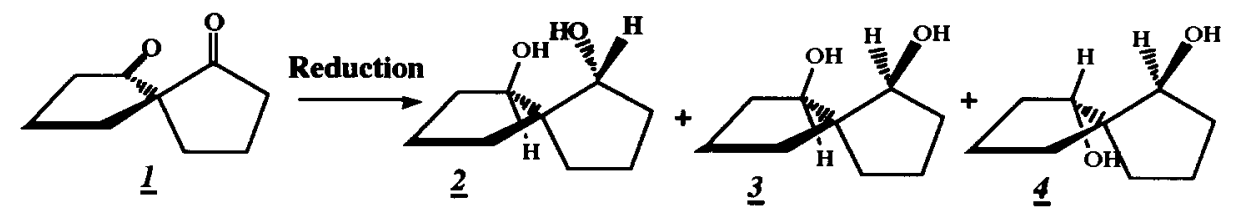

In the catalytic hydrogenation of spiro[4.4]nonane-1,6-dione, we studied both homogeneous and heterogeneous catalyst systems. When $\left[\mathrm{Ru}(S-\mathrm{BINAP}) \mathrm{Cl}_{2}\right] 2$ (NEt3) was used as a catalyst precursor in ethanol solvent, an extremely high selectivity for the cis,trans-spiro[4.4]nonane-1,6-diol product was observed (97\%). Unfortunately, under the reaction conditions a substantial amount of the starting material (62\%) decomposed via ring opening.

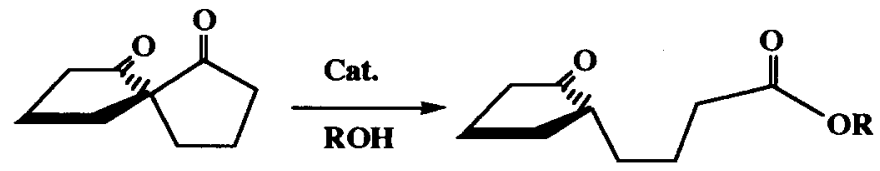

$\underline{5}$

(Spectroscopic data for methyl $\gamma$-(2-oxocyclopentyl)butyrate ( $\underline{5}$ where $\left.\mathrm{R}=\mathrm{CH}_{3}\right):{ }^{1} \mathrm{H} \mathrm{NMR}$ (in $\left.\mathrm{CDCl}_{3}\right)$ : $\mathrm{OC}_{3}$ : $3.669 \mathrm{ppm}(\mathrm{s}), 3 \mathrm{H}$; other protons: multiplets from 1.23 to $2.45 \mathrm{ppm}, 13 \mathrm{H} .{ }^{13} \mathrm{C} \mathrm{NMR}$ in $\mathrm{CDCl}_{3}$ (ppm): keto carbon (C2): 220.664; $\underline{\mathrm{CO}}_{2} \mathrm{CH}_{3}$ : 173.586; $\mathrm{OCH}_{3}$ : 51.186; $\underline{\mathrm{CH}}$ carbon (C1): 48.552; $\mathrm{CH}_{2}$ s: $37.728,33.642$, 29.129, 28.836, 22.649, 20.388. Mass spectrum: $\mathrm{M} / \mathrm{e}=184$ = calculated molecular weight.) The ringopening problem was more severe under acidic conditions. When tetrahydrofuran was used as solvent for the $\left[\mathrm{Ru}(S \text {-BINAP)Cl}]_{2}\right.$ (NEt3) catalyst system, the rate of reaction was very slow.

Raney nickel was found to be effective in ethanol solvent and to give a product distribution of 2:3:4 = 24:51:21. Platinum-on-charcoal was ineffective in ethanol solvent at ambient temperature; however, when the same reaction was carried out in acetic acid, the spiro[4.4]nonane-1,6-dione was smoothly hydrogenated to give predominantly the cis,trans-product $(2: 3: 4=24: 76: 0)$. It is of interest to note that ring-opening is not a problem here, probably due to the fast rate of hydrogenation.

In the stoichiometric hydrogenation of the dione 1 , we found that borane in tetrahydrofuran was quite effective, giving predominantly the cis, trans-diol $(2: 3: 4=16: 82: 2)$. Lithium aluminum hydride was also quite selective for the production of the cis,trans-diol (selectivity for 3 ranged from $71 \%$ to $81 \%$ ). These results complement the recent study by Nieman, Parvez, and Keay in which tert-butyldiisobutylaluminum hydride was used as the reducing agent and cis, cis-diol was the exclusive product. The typical experimental resuits are summarized in Tables 1 and 2. 
Table 1. The preparation of spiro[4.4]nonane-1,6-diols via the catalytic hydrogenation of spiro[4.4]nonane-1,6-dione

\begin{tabular}{|c|c|c|c|c|c|}
\hline catalyst & Solvent & $\begin{array}{l}\text { temp. } \\
\left({ }^{\circ} \mathrm{C}\right)\end{array}$ & $\begin{array}{l}\text { time } \\
\text { (hrs) }\end{array}$ & $\begin{array}{l}\text { yield }^{\mathrm{a}} \\
(\%)\end{array}$ & $\begin{array}{l}\text { selectivity } \\
(2: 3: 4)\end{array}$ \\
\hline$\left[\mathrm{Ru}\left(\mathrm{S}-\mathrm{BINAP} \mathrm{Cl}_{2}\right]_{2}\left(\mathrm{NEt}_{3}\right)^{b}\right.$ & benzene & 50 & 24 & 8.9 & $0: 100: 0$ \\
\hline$\left[\mathrm{Ru}(\mathrm{S}-\mathrm{BINAP}) \mathrm{Cl}_{2}\right]_{2}\left(\mathrm{NEt}_{3}\right)^{b}$ & benzene & 70 & 36 & 14.4 & $0: 100: 0$ \\
\hline$\left[\mathrm{Ru}(\mathrm{S}-\mathrm{BINAP}) \mathrm{Cl}_{2} \mathrm{l}_{2}\left(\mathrm{NE}_{3}\right)^{\mathrm{b}}\right.$ & $\mathrm{EtOH}$ & 50 & 24 & \multicolumn{2}{|c|}{$\begin{array}{c}38 \\
\text { (62\% ring-opening) }\end{array}$} \\
\hline Raney $\mathrm{Ni}$ b & $95 \% \mathrm{Et}$ & The & 18 & 88 & $24: 51: 25$ \\
\hline $\mathrm{Pt} / \mathrm{C}$ & $\mathrm{AcOH}$ & ambien & nt 3 & 97 & $24: 76: 0$ \\
\hline
\end{tabular}

(a) based on GLC analysis. b) pressure of $\mathrm{H}_{2}=1000$ psig. c) $1 \mathrm{~atm} \mathrm{H}_{2}$.

Table 2. The preparation of spiro[4.4]nonane-1,6-diols via the stoichiometric reduction of spiro[4.4]nonane-1,6-dione

\begin{tabular}{|c|c|c|c|c|c|}
\hline $\begin{array}{l}\text { reducing } \\
\text { agent }\end{array}$ & solvent & $\begin{array}{l}\text { temp. } \\
\left({ }^{\circ} \mathrm{C}\right)\end{array}$ & $\begin{array}{l}\text { time } \\
\text { (hrs) }\end{array}$ & $\begin{array}{l}\text { yield }^{a} \\
(\%)\end{array}$ & $\begin{array}{l}\text { selectivity } \\
(2: 3: 4)\end{array}$ \\
\hline $\mathrm{NaBH}_{4}$ & $\mathrm{EtOH}$ & ambient & 24 & 86 & $35: 47: 28$ \\
\hline $\mathrm{NaBH}_{4}$ & benzene & 50 & 3 & 85 & $23: 61: 16$ \\
\hline $\mathrm{LiAlH}_{4}$ & THF & ambient & 24 & 63 & $12: 78: 10$ \\
\hline $\mathrm{LiAlH}_{4}$ & THF & -78 & 24 & 70 & $27: 71: 2$ \\
\hline $\mathrm{LiAlH}_{4}$ & $\mathrm{Et}_{2} \mathrm{O}$ & ambient & 24 & 90 & $21: 71: 7$ \\
\hline $\mathrm{LiAlH}_{4}{ }^{\mathrm{b}}$ & $\mathrm{CH}_{2} \mathrm{Cl}_{2}$ & 0 & 24 & 96 & $11: 59: 30$ \\
\hline $\begin{array}{l}\mathrm{LiAlH}_{4}{ }^{\mathrm{b}} \\
\mathrm{LiAlH}_{4}\end{array}$ & $\begin{array}{l}\mathrm{CH}_{2} \mathrm{Cl}_{2} \\
\text { benzene }\end{array}$ & $\begin{array}{l}-78 \\
50\end{array}$ & $\begin{array}{l}24 \\
4\end{array}$ & $\begin{array}{l}45 \\
81\end{array}$ & $\begin{array}{l}5: 81: 14 \\
0: 69: 31\end{array}$ \\
\hline $\mathrm{BH}_{3} \cdot \mathrm{THF}$ & THF & $40-50$ & 1.4 & 90 & $16: 76: 8$ \\
\hline $\mathrm{BH}_{3} . \mathrm{THFd}$ & THF & $40-50$ & 1.4 & 92 & $16: 82: 2$ \\
\hline DIBAH $^{\mathrm{e}}$ & THF & -78 & 24 & 100 & $30: 50: 20$ \\
\hline DIBAH & THF & -78 & 24 & 100 & $35: 46: 19$ \\
\hline DIBAH & hexane & -78 & 24 & 95 & $44: 43: 13$ \\
\hline DIBAH & hexane & -10 & 24 & 97 & $56: 34: 10$ \\
\hline DIBAH & hexane & 0 & 24 & 98 & $62: 30: 8$ \\
\hline DIBAH & hexane & 13 & 24 & 100 & $59: 35: 6$ \\
\hline DIBAH $^{\mathrm{f}}$ & hexane & -78 & 24 & 95 & $44: 43: 13$ \\
\hline DIBAH & benzene & 0 & 24 & 97 & $37: 57: 6$ \\
\hline
\end{tabular}

(a) based on GLC analysis. (b) one equivalent of $\mathrm{TiCl}_{4}$ (against the dione) was added. (c) a small amount of ( + )-tartaric acid was added. (d) one equivalent of d-1,2-diphenyl-2-aminoethanol (against the dione) was added. (e) one equivalent of $\mathrm{LiH}$ (against the dione) was added. (f) a small amount of toluene was added to the solvent.

Since the trans,trans-diol is potentially a very useful precursor for the preparation of other useful chelating chiral ligands such as phosphines and amines, it is important to resolve the two enantiomers and characterize them fully. To this end we isolated the $d$-10-camphorsulfonate of these compounds in single crystal forms. When a racemic trans, trans-diol was allowed to react with two equivalents of $d$-10-camphorsulfonyl chloride, diastereomers of the $d$-10-camphorsulfonates of the two diol enantiomers were obtained. 

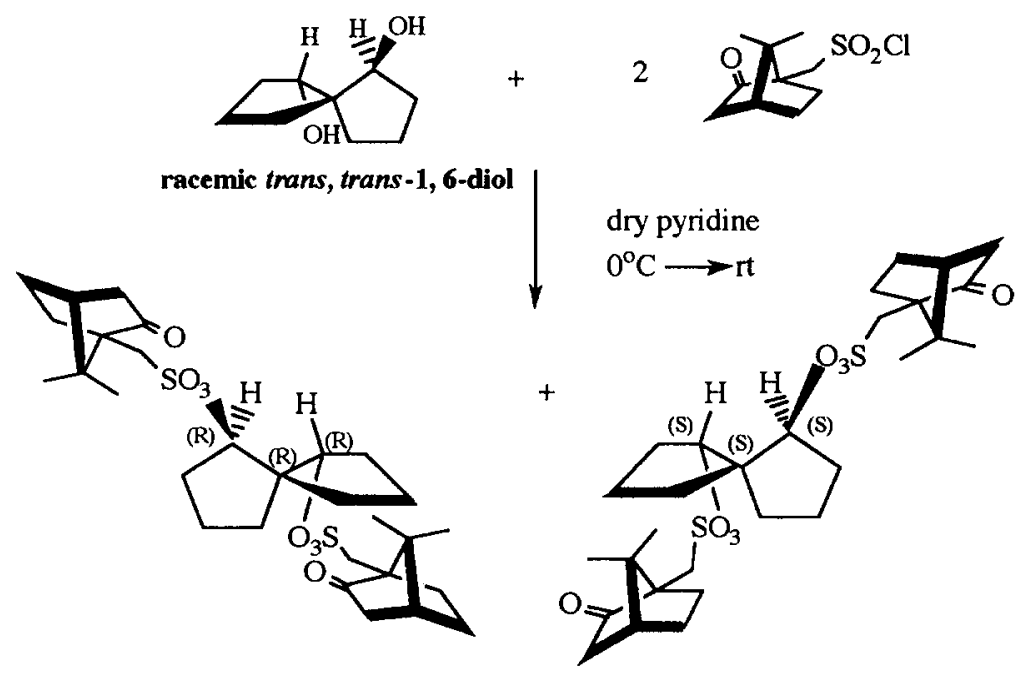

When this mixture was re-crystallized from ethyl acetate, single crystals were formed. An X-ray diffraction study revealed that both diastereomers were packed in the unit cells of the single crystals and the structures of these compounds were unambiguously characterized. The two diastereomers were separated by column chromatography and the single crystals of the pure 1S, 5S, 6S-isomer was obtained after collection and recrystallization. The structure of this isomer was again unambiguously characterized by $\mathrm{X}$-ray diffraction (Figure).

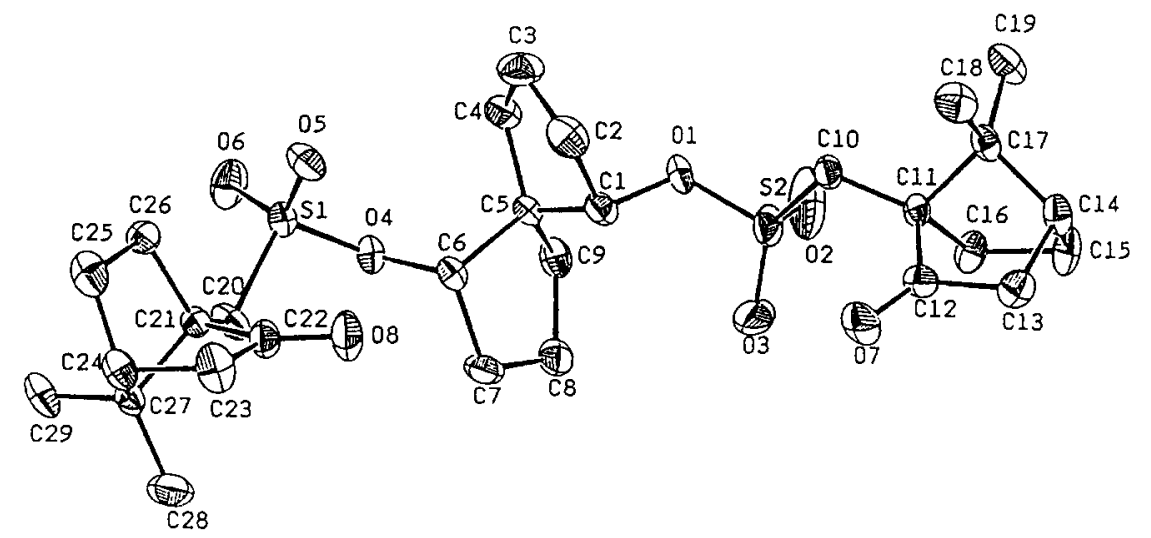

Figure. A perspective view of $1 \mathrm{~S}, 5 \mathrm{~S}, 6 \mathrm{~S}$-trans, trans-1,6-di-d-camphorsulfonato-spiro[4,4]nonane

Pure 1S, 5S, 6S- and $1 R, 5 R, 6 R$-trans, trans-spiro[4,4]nonane-1,6-diols were obtained by cleaving the $d$ camphorsulfonato groups with sodium naphthalide in THF at $-80^{\circ} \mathrm{C}$ followed by the treatment with ice-water and extraction with ethyl acetate. ${ }^{7}$ This study unambiguously confirmed the absolute configuration of these diols. 
Together with the previous X-ray characterization of the structure of a derivative of the cis,cis-diol, the definitive elucidation of the structure of the trans,trans-isomer gave a clear picture of the relative stereochemistry of spiro[4.4]nonane-1,6-diols.

In conclusion, the hydrogenation of spiro[4.4]nonane-1,6-dione is a complex reaction and the product selectivity is highly dependent on the reducing agents and the reaction conditions. With proper choices of reagents, high selectivity for the cis,trans-diol can be obtained. This complements well the previous study which gave high selectivity for the cis,cis-diol.2a

\section{Experimental Section}

The spiro[4.4]nonane-1,6-dione was prepared according to previously published methods. ${ }^{6,8}$

Unless otherwise indicated, all experiments were carried out under dried dinitrogen atmosphere and all solvents were purified and dried by standard methods before use.

\section{A typical procedure for the reduction of spiro[4.4/nonane-1,6-dione.}

A 500-mL two-necked, round-bottomed flask was charged with $4.02 \mathrm{~g} \mathrm{LiAlH}_{4}$ and $100 \mathrm{~mL}^{\text {diethyl }}$ ether under an atmosphere of dry $\mathrm{N}_{2}$. While the mixture was stirred at ambient temperature with a magnetic stirrer, $8.04 \mathrm{~g}$ of spiro[4.4]nonane-1,6-dione in $50 \mathrm{~mL}$ diethyl ether was slowly added to the stirring over a period of one hour. After all of the diketone was added, the stirring was continued for another four hours. The mixture was then cooled to about $0-2^{\circ} \mathrm{C}$ with an ice bath. About $16 \mathrm{~mL}$ of ethyl acetate was added to destroy the excess $\mathrm{LiAlH}_{4}$ and $160 \mathrm{~mL}$ of $10 \%$ sulfuric acid was added to neutralize the base. The mixture was then extracted twice with diethyl ether ( $500 \mathrm{~mL}$ each time) and the resulting ether solution was dried over magnesium sulfate. The solvent was evaporated in a rotary evaporator to give $7.4 \mathrm{~g}$ of mixed diols which was further purified via liquid chromatography.

\section{Atypical procedure for the separation of the diols via liquid chromatograph.}

The mixed diols obtained from the reduction of spiro[4.4]nonane-1,6-dione was separated on a silica gel column by stepwise elution with the sequential eluents as follows: (1) petroleum ether : ethyl acetate $=10: 1 ;(2)$ petroleum ether : ethyl acetate $=5: 1 ;(3)$ petroleum ether : ethyl acetate: ethanol $=5: 1: 0.2$. The products were separated and were collected in the following order: cis, cis first; cis, trans second; and trans, trans last. The ${ }^{1} \mathrm{H} \mathrm{NMR}$ (in $\mathrm{CDCl}_{3}$ ) data for the three isomers are as follows:

cis, cis: $\underline{\mathrm{H}}-\mathrm{C}-\mathrm{OH}: 4.151 \mathrm{ppm}$; dd; $\mathrm{J}_{1}=4.6 \mathrm{~Hz} ; \mathrm{J}_{2}=2 \mathrm{~Hz}$. trans, trans: $\underline{\mathrm{H}}-\mathrm{C}-\mathrm{OH}: 3.816 \mathrm{ppm}$; dd; $\mathrm{J}_{1} \sim \mathrm{J}_{2}=6.1 \mathrm{~Hz}$. cis, trans: $\underline{\mathrm{H}}-\mathrm{C}-\mathrm{OH}$ (cis): $4.265 \mathrm{ppm}$; dd; $\mathrm{J}_{1} \sim \mathrm{J}_{2}=8.2 \mathrm{~Hz} . \underline{\mathrm{H}}-\mathrm{C}-\mathrm{OH}$ (trans): $3.910 \mathrm{ppm}$; dd; $\mathrm{J}_{1} \sim \mathrm{J}_{2}=4 \mathrm{~Hz}$.

\section{Preparation of trans, trans-1,6-di-d-camphorsulfonato-spiro[4,4/nonane}

A $100-\mathrm{mL}$ round bottomed flask was charged with $4.236 \mathrm{~g}$ of $d$-camphorsulfonyl chloride and $20 \mathrm{~mL}$ dry pyridine. The solution was cooled in an ice bath and $1.2 \mathrm{~g}$ of spiro[4.4]nonane-1,6-diol was added slowly under an atmosphere of dry nitrogen. The mixture was stirred for four hours and a white, colloidal solution was obtained. About $30 \mathrm{~g}$ of ice was added to the mixture and some white precipitate was observed. The mixture was allowed to stand for 12 hours to insure complete precipitation. The white precipitate was filtered and washed with small amounts of water and ether. The wet cake was dried in vacuo to give $3.992 \mathrm{~g}$ white solid. (Isolated yield of trans, trans-1,6-di- $d$-camphorsulfonato-spiro[4,4]nonane was $88.9 \%$ ) 


\section{Separation of the two diastereomers of trans, trans-1,6-di-d-camphorsulfonato-spiro/4,4/nonane}

A glass column with 60-cm length and 5-cm inside diameter was loaded with $400 \mathrm{~g}$ silica gel (0.063-0.2 $\mathrm{mm}$ ) and the column was washed with a mixture of eluent solvents (petroleum ether : cyclohexane : ethyl acetate $=4: 3: 2$ ). Two grams of the trans, trans-1,6-di- $d$-camphorsulfonato-spiro[4,4]nonane obtained from experiment 3 was dissolved in $15 \mathrm{~mL}$ dichloromethane and the solution was loaded in the column. The elution of the diastereomers was carried out with the mixed solvents. The first four liters of solution (which contained no desired material) was discarded. The eluate solution was then collected in $20 \mathrm{~mL}$ test tubes with an automatic collector. No product was observed in the first 20 tubes. Pure 1,6-di-d-camphorsulfonato-1S, 5S, 6Sspiro[4,4]nonane was obtained in the first collection (21st to 95th sample tubes). The second collection (96th to 145th tubes) contained a mixture of the two diastereomers. The third collection (146th to 200th tubes) contained pure 1,6-di- $d$-camphorsulfonato-1R, 5R, 6R-spiro[4,4]nonane. Single crystals of 1,6-di- $d$-camphorsulfonato$1 \mathrm{~S}, 5 \mathrm{~S}, 6 \mathrm{~S}$-spiro[4,4]nonane was obtained by evaporating off the solvents in the first collection and recrystallized the product in ethyl acetate/petroleum ether. The physico-chemical data for the two isomers are as follows: 1,6 -di- $d$-camphorsulfonato-1S, $5 \mathrm{~S}, 6 \mathrm{~S}$-spiro[4,4]nonane: melting point $=142.6^{\circ} \mathrm{C},[\alpha] \mathrm{D}^{27}=+70.2$ $\left(\mathrm{C}=0.061, \mathrm{CH}_{2} \mathrm{Cl}_{2}\right)$. 1,6-di- $d$-camphorsulfonato-1R, 5R, 6R-spiro[4,4]nonane: melting point $=122.3{ }^{\circ} \mathrm{C}$, $[\alpha] D^{27}=+4.9\left(\mathrm{C}=0.052, \mathrm{CH}_{2} \mathrm{Cl}_{2}\right)$.

\section{Characterization of 1,6-di-d-camphorsulfonato-1S, 5S, 6S-spiro[4,4]nonane by single crystal $X$ - ray} diffraction.

The single crystal X-ray diffraction data of 1,6-di-d-camphorsulfonato-1S, 5S, 6S-spiro[4,4]nonane was collected on a four-circle diffractometer (CAD4) using $\mathrm{CuK} \alpha(\lambda=1.5418 \mathrm{~A})$. (Crystal data: space group $P 6_{1} ; \mathrm{a}=11.988(3) ; \mathrm{c}=34.967(6) \mathrm{A} ; \mathrm{Z}=6 ; 2 \Theta_{\max }=130^{\circ}$.) A total of 2512 unique reflections were measured, among these 2370 were observed reflection $(I>2 \sigma(I))$ and were used for the least square refinement. The final agreement index was 0.039 .

\section{Cleavage of the d-camphorsulfonato group from 1,6-di-d-camphorsulfonato-1R, $5 R, 6 R$ -} spiro/4,4 Jnonane to produce the pure $1 R, 5 R, 6 R$-diol

A $100 \mathrm{~mL}$ round bottom flask equipped with an addition funnel was charged with $475 \mathrm{mg}$ of 1,6-di- $d$ camphorsulfonato-1R, 5R, 6R-spiro[4,4]nonane and $10 \mathrm{~mL}$ dry THF. The mixture was stirred with a magnetic stirrer to give a clear solution which was cooled to $-80^{\circ} \mathrm{C}$. While the solution was continued to stir at $-80^{\circ} \mathrm{C}$, a solution of sodium naphthalide (which was prepared by reacting $0.52 \mathrm{~g}$ sodium metal with 3 grams of naphthalene in $75 \mathrm{~mL}$ dry THF) was slowly added to it and the mixture was continued to stir at $-80^{\circ} \mathrm{C}$ for 10 hours. The stirred solution was allowed to return to ambient temperature and $50 \mathrm{~mL}$ of ice-water was added to it. The mixture was extracted with $30 \mathrm{~mL}$ ethyl acetate three times and the combined organic solvents were evaporated. After a purification through column chromatography on silica gel, $75 \mathrm{mg}$ of pure white solid was obtained $\left([\alpha]_{D}{ }^{20}=-60(C=0.026, E t O H)\right.$. (Isolated yield $=59 \%$.) Similar results were also obtained on the isolation of pure $1 \mathrm{~S}, 5 \mathrm{~S}, 6 \mathrm{~S}$-spiro[4,4]nonanediol. The signs and the values of specific rotation are in agreement with previously published data. $8 \mathrm{C}$ 


\section{Acknowledgment.}

We thank Dr. W. S. Knowles of St. Louis and Dr. S. C. F. Au-Yeung of the Chinese University of Hong Kong for helpful discussions. Financial supports from the Hong Kong Research Grant Council, the National Science Council, and Academia Sinica are greatly appreciated.

\section{References.}

1. For recent reviews, see a) Noyori, R. Asymmetric Catalysis in Organic Synthesis; Wiley: New York, 1994. b) Ojima, I.; Ed.; Catalytic Asymmetric Synthesis; VCH Publisher: New York, 1993.

2. a) Nieman, J. A.; Parvez, M.; Keay, B. A. Tetrahedron: Asymmetry 1993, 4, 1973-1976.

b) Brunner, R.; Gerlach, H. Tetrahedron: Asymmetry 1994 5, 1613-1620.

3. In previous publications, chiral centers of these compounds were mislabeled as $1 \mathrm{~S}, 5 \mathrm{~S}, 6 \mathrm{~S}$ and $1 \mathrm{R}$, 5R, 6R, respectively (e.g. ref. 2a).

4. Srivastava, N.; Mital, A.; Kumar, A. J. C. S. Chem. Comm. 1992, 493.

5. a) Noyori, R. Science 1990, 248, 1194. b) Noyori, R.; Takaya, H. Acc. Chem. Res. 1990, 23, 345. c) Noyori, R. Science 1992, 258, 584.

6. Cram, D. J.; Steinberg, H. J. Am. Chem. Soc. 1954, 76, 2753.

7. Closson, W. D.; Wriede, P.; Bank, S. J. Am. Chem. Soc. 1966, 88, 1581.

8. a) Carruthers, W.; Orridge, A. J. Chem. Soc. Perkin Trans. 1977, 1, 2411. b) Gerlach, H. Helv. Chim. Acta. 1968, 51, 1578. c) Gerlach, H.; Muller, W. Helv. Chim. Acta. 1972, 55 , 2279.

(Received in Japan 16 August 1995; accepted 4 October 1995) 